\title{
Marketing Strategies and Market Performance of M-Sente a Mobile Money Product of Uganda Telecom Ltd.
}

\author{
Bob Eustace Waiswa, Alex Nduhura*, Benedict Mugerwa, John Paul Settumba, \\ Paul Wanume, Hannington Businge \\ Uganda Management Institute, Uganda
}

Copyright $(2016$ by authors, all rights reserved. Authors agree that this article remains permanently open access under the terms of the Creative Commons Attribution License 4.0 International License

\begin{abstract}
Purpose- Intrigued by the poor market performance of M-Sente product of Uganda Telecom Limited (UTL), this study examined the relationship between marketing strategies and the market performance of M-Sente, a mobile money product of Uganda Telecom Limited. Specifically, study: examined the relationship between pricing and market performance of M-Sente; examined the relationship between promotion and market performance of M-Sente; and, examined the relationship between place and market performance of M-Sente. Design/methodology- The study adopted a cross section study design and both quantitative and qualitative approaches. In total, a sample of 120 respondents was chosen and included members of the marketing team, Sales team, dealers (Central), sub dealers (Central) and M-Sente outlets (Central). Data was collected by means of questionnaires and interviews, and analysis of quantitative data was done using descriptive and inferential statistics. Findings - This paper revealed that UTL's prices were lower than the competition, though customers did not feel they were getting value for money. This explains why UTL's market share continues to decline despite their competitive prices. The study findings revealed that there is a positive relationship between marketing strategies and market performance of M-Sente mobile money product of UTL. Further, it was noted that pricing had a positive correlation with market performance $\left(\mathrm{r}=0.444^{* *} ; \mathrm{p}<.001\right)$; promotion had a positive significant relationship with market performance $(\mathrm{r}=.171 * ; \mathrm{p}<.001)$; and place was positively correlated with market performance in UTL, though not significantly $(\mathrm{r}=.366 ; \mathrm{p}>.001)$. The findings of this paper show that the price of M-Sente products was found to be low although the number of customers kept on declining. This is contrary to the law of demand that postulates that the lower the price the higher the demand. Results showed that M-Sente had a small number of retail outlets distributed all over Kampala. It was not featuring significantly in the rural areas, because most people in the rural areas have no bank accounts and largely rely on mobile money transactions.
\end{abstract}

This means that even if a customer wanted to use M-Sente, they had to travel far in search of an M-Sente outlet. There is revelation that customers would rather use the competitors' mobile money services (more widely spread out in every town and more accessible). The promotional strategies through advertising had proved to be very costly to UTL, yet the results from them were so minimal, contributing to significant losses. Thus, UTL needs to explore other less costly means of sales promotion, such as handing out samples of its products, having promotional products branded with its logo, or other gifts at key locations. One of the major drawbacks for UTL's M-Sente services was the limited accessibility. Therefore, the company should carry out thorough planning on the location of the mobile money outlets. The results (findings) of this research can't be generalized. Implications- Pricing is one of the marketing strategies that UTL is using to improve its market performance, by charging rates lower than the rest of the telecom companies, though this has not resulted into better market performance. UTL has engaged in a number of promotions for example sales promotion, advertising promotion and on line promotions, in an effort to inform, persuade and influence people when making a decision to buy. However, the fewer outlets in the city centre seemed to be countering the efforts through promotion. This calls for better planning on the location of the mobile money outlets within and outside Kampala. In addition, the outlets need to be strategically located in places where it is easy to outwit competitors given the marketing strategies employed.

Keywords M-Sente, Marketing Strategies, Market Performance, Customer Reality

\section{Introduction}

Over the years, marketing strategies have served as the fundamental underpinning of marketing plans that are 
designed to fill market needs and reach marketing objectives. Today, marketing is the biggest paradigmatic shift in marketing theory and practice, but marketing cannot be discussed without considering market performance and customer satisfaction (Holbrook, 2000). Marketing strategy includes all basic and long-term activities in the field of marketing that deal with the analysis of the strategic initial situation of a company and the formulation, evaluation and selection of market-oriented strategies and therefore contributes to the goals of the company and its marketing objectives. Krippendorf (2009) defines marketing strategy as a process that can allow an organization to concentrate its resources on the optimal opportunities with the goals of increasing sales and achieving a sustainable competitive advantage. In this study, marketing strategies will refer to pricing, promotion and place as advanced by Dunstan (1996). According to Olson \& Reynolds (2003), market performance refers to the behavior of a security or asset in the marketplace. In this study, market performance was measured in terms of customer retention, sales force effectiveness, key customer profitability, sales revenue and market share. This paper examines the relationship between marketing strategies and market performance of M-Sente a Mobile Money Product of Uganda Telecom Ltd.

\section{Background}

Marketing strategy includes all basic and long-term activities in the field of marketing and thus contributes to the goals of the company and its marketing objectives. According to Lewalski (2008), marketing strategies serve as the fundamental underpinning of marketing plans designed to fill market needs and reach marketing objectives. Marketing strategy involves careful and precise scanning of the internal and external environments.

In East Africa, the introduction of mobile money services started in 2007, with the launch of M-PESA (Mudiri, 2014); clearly a success M-PESA is now used by $83 \%$ of the Kenyan population and processes $\$ 15$ billion in payment flows annually (which constitute $25 \%$ of Kenya's GDP) (Sandeep, et al 2015). Kendall, et al (2011) observe that the M-PESA network handles more transactions in a year than Western Union does globally, and the value of transactions represents more than $15 \%$ of Kenya's GDP.

In Uganda, there are four major Mobile Network Operators (MNOs), that is, MTN Uganda, Africell, Uganda Telecom and Airtel, each having a sizeable number of customers. One of the key MNOs is Uganda Telecom with M-sente as the mobile money product of UTL. Uganda Telecom was the third MNO in the country to offer mobile money transfer services, intensifying the growing battle in this particular market segment. To avail the service, UTL partnered with Map Switch, an international financial infrastructure provider, and DFCU Bank (UCC Report, 2013). Customers using the M-Sente service were charged according to the amounts withdrawn or sent. Registered users paid as low as UGX 500 for transactions below shillings 30,000 . Non-registered users of the service were charged UGX 600. By 2012customers could transfer up to UGX 2 million per day through the M-Sente service. Against this market background, the challenge for many mobile telecommunication companies is to find ways and means of sustaining or increasing existing enrolment levels for customers and it is this matter that UTL is trying to solve.

Of the four MNOs, only three currently have a mobile money offering; MTN Mobile Money (MTN Uganda 2010), M-Sente from UTL (Uganda Telecom, 2010) and Airtel money (formerly Zain Uganda 2010).To comply with financial services regulation, the MNOs have partnered with banks. MTN is working with Stanbic Bank, UTL with DFCU and Airtel with Standard Chartered Bank. MTN has the largest number of registered mobile money users with over 2,000,000 customers, setup over 1,500 agents/outlets across the country and transferred more than UGX 590 billion (US\$ 245 million) since its launch in March 2009 (MTN Uganda 2010). Zain (now Airtel) launched Zap in July 2009, while UTL launched M-Sente in March 2010 (Uganda Telecom, 2010).

As of 2014, there were 12.1 million mobile phone subscribers across all five mobile network operators and the subscriber base has been steadily increasing (Uganda Government, 2013). In the past four years, UTL has witnessed declining sales levels and customer retention rates right from the stock shelves of their wholesalers and various outlets; and their stock replaced by competitors stock like MTN and Airtel Money (Uganda Communication Commission Report, 2013). Olupot (2013) attributed the decline in market performance to the marketing strategies employed by the company. However, limited or no other empirical studies had been undertaken to corroborate this assertion. It is against this background that this study was conducted, so as to examine the relationship between marketing strategies and market performance of M-Sente, a Mobile Money product of Uganda Telecom Ltd.

\section{The Problem}

Over years Uganda Telecom Ltd has devised product, price, and promotion and place strategies to ensure good market performance. Despite such strategies, Musana (2013) highlights incremental poor market performance evidenced by high customer turnover, customer attrition, customer complaints and low sales (decreasing purchases). According to a survey carried out by Uganda Communications Commission (2013), it was established that $96 \%$ of mobile phone users were registered on mobile money. Among the households with registered mobile money users, $93 \%$ were found to use one mobile money service provider, $6 \%$ used two different providers and $1 \%$ used three mobile money providers. MTN registered the highest number of registered mobile money users followed by Airtel, while UTL came in the third position. Currently the mobile money market share of UTL is the lowest in the market with MTN having the largest share of $74 \%$, followed by Airtel Money with $19 \%$ and lastly UTL's M-Sente with the lowest market share of 
$7 \%$. By the end of 2013 , the market share of UTL had significantly reduced to $5.3 \%$ (Uganda Communication Commission Report, 2013). UTL has made efforts to invest in market research and make countrywide promotions (UTL, 2013). However, there is fear that if the market trend remains as it is, there is a likelihood that the market performance of UTL will greatly dwindle to the extent of being pushed out of the market. This will eventually lead to insolvency of the company and possibly closing shop. It is against this background that the study sought to examine the relationship between marketing strategies and market performance of M-Sente a Mobile Money Product of Uganda Telecom Ltd so as to come up with mitigation measures to the problem.

\section{Methodology}

The target population comprised of 160 respondents, these included; 10 members of the marketing team, 25 UTL Sales team, 10 UTL dealers (Central), 35UTLsub dealers (Central) and $80 \mathrm{M}$-Sente Outlets (Central). The study was based on a sample size of 120 that was drawn from a population of 160 . Data was majorly collected by means of a questionnaire which was distributed to 10 members of the marketing team, 15 UTL Sales team, 10 UTL dealers (Central), 22UTL sub dealers (Central) and $64 \mathrm{M}$-Sente Outlets (Central). In addition, interviews were conducted with 02 members of the marketing team, 03 UTL Sales team, 03 UTL dealers (Central), 04 UTL sub dealers (Central) and 06 M-Sente Outlets (Central). Quantitative data was analysed using descriptive and inferential statistics. Regression analysis and Correlations (Pearson's Product Moment Correlation Co efficient) were used to measure the degree of relationship between the independent variables and dependent variables.

\section{Review of Related Literature}

This study was largely underpinned by Michael Porter's (1985) value chain analysis concept. Porter suggests that activities within an organization add value to the service and products that the organization produces and all these activities should be run at optimum level if the organization is to gain any real competitive advantage (Porter, 1985 as cited in Schmidt \& Heyder, 2003). If they are run efficiently the value obtained should exceed the costs of running them i.e. customers should return to the organization and transact freely and willingly (Schmidt \& Heyder, 2003).

\section{Pricing and Market Performance}

According to Bloch (2005), pricing is one of the most important elements of the marketing mix, as it is the only mix which generates a turnover for the organization. The remaining 3p's, that is, product, promotion and place are variable costs for the organization. It costs to produce and design a product; it costs to distribute a product and costs to promote it. Price must support these elements of the mix.
Pricing is crucial and must reflect supply and demand relationship. Pricing a product too high or too low could mean a loss of sales for the organization.

Relatedly, Jenigarn \& Easterling (2000) opine that the price of an item is clearly an important determinant of the value of sales made; asserting that in theory, price is really determined by the discovery of what customers perceive is the value of the item on sale. Researching consumers' opinions about pricing is important as it indicates how they value what they are looking for as well as what they are willing to pay. However, an organization's pricing policy will vary according to time and circumstances.

Further, Kotler and Ruth (2004) hold the view that penetration pricing involves setting a low price to increase sales and market share. Once market share has been captured the firm may well then increase their price. A television satellite company sets a low price to get subscribers then increases the price as their customer base increases. Pricing is an important element when marketing services because the purchaser of a professional service is in fact buying the capabilities of the seller, he or she has to closely evaluate the behavior and characteristics of the sales person, the business, its reputation, facilities and appearance before purchasing.

According to Holbrook (2000) competitive pricing involves setting a price in comparison with competitors. A firm has three options and these are to price lower, price the same or price higher. However, some firms offer a price matching service to match what their competitors are offering. In the same breath, Jernigan \& Easterling (2000) argue that product line pricing involves pricing different products within the same product range at different price points. The greater the features and the benefit obtained, the greater the consumer will pay.

\section{Promotion and Market Performance}

According to Kotler \& Ruth (2004) promotion is a method used to spread the word about a product or service to customers, stakeholders and the broader public. Once one has identified a target market, he/she will have a good idea of the best way to reach them, but most businesses use a mix of advertising, personal selling, referrals, sales promotion and public relations to promote their products or services. However, in this study, promotion was looked at alongside pricing and product attribute.

Further, Kotler \& Ruth (2004) opine that promotion is characterized by advertising, publicity and sales promotion. Advertising involves non-personal communication transmitted through mass media. Publicity involves free promotion through news stories in newsletters, newspapers, magazines and television. Sales promotion involves all forms of communication not found in advertising and personal selling, including direct mail, coupons, volume discounts, sampling, rebates, demonstrations, exhibits, sweepstakes, trade allowances, samples and point-of purchase displays. Relatedly, Kotler \& Ruth (ibid) assert that promotion is a method used to spread the word about a 
product or service to customers, stakeholders and the broader public. Once one has identified a target market, he/she will have a good idea of the best way to reach them, but most businesses use a mix of advertising, personal selling, referrals, sales promotion and public relations to promote their products or services. However, in this study, promotion was looked at alongside pricing and product attribute.

\section{Place and Market Performance}

Place refers to how an organization will distribute the product or service they are offering to the end user (Bloch, 2005). The organization must distribute the product to the user at the right place at the right time. Efficient and effective distribution is important if the organization is to meet its overall marketing objectives. If an organization under estimates demand and customers cannot access the product when they want it, profitability will be affected (Bloch, ibid).On the other hand the term 'place' was used in this study to refer to location and distribution. However, that notwithstanding, access to mobile money may not automatically translate into usage. Rather, usage is something that needs nurturing and by many players.

Place is the element of the marketing mix that ensures that the product is distributed and made conveniently available for the consumer - at the right location at the right time (Jernigan \&Easterling, 2000). It is imperative that when the consumer comes to purchase a product, that product is readily available without any issue. Whenever consumers are faced with issues involving the availability of a product, it's almost certain that they will take their business somewhere else (Jernigan \&Easterling, ibid) adding that it is so important the product makes it to the right place at the right time.

\section{Findings}

The results showed that the correlation coefficient for pricing and market performance was $0.444^{* *}$, significant at 0.01 level, indicating a positive significant relationship between pricing and market performance. This implied that pricing positively influences market performance. In addition, results from the descriptive statistics and qualitative results from interviews with key informants showed that UTL had the lowest market prices, in an effort to attract more customers. However, one respondent in an interview shared that the pricing strategy did not seem to be very effective, given the stiff competition on the market, adding that what the company needed was a combination of strategies in order to gain competitive advantage.

The results further showed that the correlation coefficient for promotion and market performance was $0.171^{*}$, which pointed to a positive and significant relationship and thus implied that promotion influences the market performance of M-sente. However, related results from interviews showed that promotion had not yielded better results in terms of UTL's market performance; instead, the company had registered losses to a tune of 23 billion shillings. It was also noted that given the financial position of UTL, advertising was considered a rather expensive venture, especially in the light of the huge losses they had encountered.

Finally, the results showed that the correlation coefficient for 'place' was 0.366 , though not statistically significant. This implied that place positively correlates with market performance, though not statistically sufficient to cause significant change in market performance. Results from interviews held with some of the agents showed that UTL was only popular in Kampala, and even then, few people would demand for M-Sente services. Descriptive statistics results showed that $70 \%$ of the respondents considered M-Sente services to be inaccessible, a factor that could have a great bearing on the low market performance.

On the other hand, results from interviews indicated $70.3 \%$ of customers would prefer to use M-Sente competitors mobile money products like MTN Mobile money and Airtel Money due to ease of access. Statements such as "Convenience and urgency is more important when I need money" were dominant. Sixty five $(65 \%)$ were unaware of promotions that UTL was implementing. On the large $85.4 \%$ of respondents were not aware of M-Sente promotions. $68 \%$ of the respondents that were not aware of M-Sente promotions were aware of M-Sente competitor promotions such MTN Mobile money and Airtel Money. The findings revealed that there existed a distance relationship between UTL and its customers with one agent lamenting "what matters to UTL is my money".

\section{Discussion}

The price of M-Sente products was found to be low although the number of customers kept on declining. This is contrary to the law of demand that postulates that the lower the price the higher the demand. According to Bloch (2005), pricing is one of the most important elements of the marketing mix, as it is the only mix, which generates a turnover for the organization. The remaining 3p's are the variable cost for the organization. It costs to produce and design a product; it costs to distribute a product and costs to promote it. Price must support these elements of the mix.

In tandem with the results on pricing and market performance of UTL's M-Sente product, Jenigarn and Easterling (2000) noted that the price of an item is clearly an important determinant of the volume of sales made. In theory, price is really determined by the discovery of what customers perceive is the value of the item on sale. Researching consumers' opinions about pricing is important as it indicates how they value what they are looking for as well as what they are willing to pay. So even though UTL's prices were lower than the competition, customers did not feel they were getting value for money. This could explain why UTL's market share continues to decline despite their 
competitive prices.

Sales Promotion involves all forms of communication not found in advertising and personal selling, including direct mail, coupons, volume discounts, sampling, rebates, demonstrations, exhibits, sweepstakes, trade allowances, samples and point-of purchase displays (Kotler, 2004). This study revealed that UTL had cut back on advertising and were not taking advantage of the internet to advertise their product. This could explain their declining performance.

Results further showed that M-Sente had a small number of retail outlets distributed all over Kampala. Moreover, it was not featuring significantly in the rural areas, yet most people in the rural areas have no bank accounts and largely rely on mobile money transactions. This means that even if a customer wanted to use M-Sente, if they had to travel far in search of an M-Sente outlet. In such circumstances, they would rather use the competitors' mobile money services which are more widely spread out in every town and city centre and more accessible.

\section{Implications}

UTL needs to regularly carry out market research to find out how prices are affecting the business, what customers want and how they feel about the product and the price. UTL should incorporate their ideas into the ongoing market research because the lower price strategy is not working, since results showed that although UTL had the lowest prices for the mobile money services, the demand remained low and in contrast to the law of demand. Thus, UTL should try other avenues of improving market performance like advertising and further investment in market research.

One of the major drawbacks for UTL's M-Sente services was the limited accessibility. Therefore, the company should carry out thorough planning on the location of the mobile money outlets within and outside Kampala. The out lets should be strategically located in places where it is easy to outwit competitors given the marketing strategies employed. There is a need for UTL to undertake trade-offs and explore virtual distribution channels such as website selling and emerging innovative network based distribution strategies such as creating partnerships with banks. With such a channel customers can be able to use their bank auto teller machines (ATM) to engagement with UTL service options

Enhancing reach to customers will require UTL to sign up more agents. Recruiting Incentivising agents with improved margins like those offered by MTN Mobile money and Airtel Money (ranging from 5\%-10\%. This would help in reducing the constraint of reach and accessibility that increases M-Sente preference for competitor products such as MTN Mobile money and Airtel Money and telco services

It was noted that promotional strategies through advertising had proved to be very costly to UTL, yet the results from them were so minimal, contributing to significant losses. Thus, UTL needs to explore other less costly means of sales promotion, such as handing out samples of its products, having promotional products branded with its logo, or other gifts at key locations. This lets people experience what they have to offer and creates brand awareness. In addition, it is imperative for UTL to reward customer loyalty by encouraging customers to trade in their old product for a discount on something new.

Finally, UTL needs to undertake periodic customer satisfaction surveys. By undertaking such surveys, UTL can be able to know its "customer reality". We define customer reality as a "state of disappointment, ideas, concerns, and complaints". The firm can use the Net Promoter Score (NPS) tool would help to retrieve customer reality. Once, customer reality is retrieved, it should help to inform strategy aimed at providing dazzling experiences. Such experiences are necessary for initial and sustained repeat sales of UTL products(critical for sustained revenue generation, profit, and market share growth). The process of customer satisfaction surveys provides an opportunity for developing broken relationships and help to create a feel of ownership, and care of thought amongst customers.

\section{REFERENCES}

[1] Mudiri, Joseck L. (2012). Fraud in Mobile Financial Services. Luknow, India: MicroSave, December.

[2] Bloch, P. H. (2005). Seeking the ideal form-Product design and consumer response. Journal of Marketing, 59(3), 16-29.

[3] Dunstan, F. (1996).The Loyalty Effect: The hidden force behind growth, profits and lasting value. Harvard: Business Harvard Review Issue 2 (33) - 41.

[4] Holbrook, M. B. (2000). Some preliminary notes on research in consumer esthetics. In J. C. Olson (Ed.), Advances in consumer research (pp. 104-108). Ann Arbor, MI: Association for Consumer Research.

[5] Jernigan, M. H., \& Easterling, C. R. (2000). Fashion merchandising and marketing. New York: Macmillan.

[6] Kotler, P., \& Ruth, G. A. (2004). Design: A powerful but neglected strategic tool. Journal of Business Strategy, 5(2), $16-21$.

[7] Krippendorf, K. (2009). On the essential contexts of artifacts or on the proposition that "design is making sense (of things)". Design Issues, 5(2), 9-39.

[8] Lewalski, Z. M. (2008). Product esthetics: An interpretation for designers. Carson City, NV: Design \& Development Engineering Press.

[9] Olson, J. C., \& Reynolds, T. J. (2003).Understanding consumers' cognitive structures: Implications for advertising strategy, in L. Percy \& A. G. Woodside (Eds.), Advertising and consumer psychology (pp. 77-90). Lexington, MA: Lexington Books. 
[10] Schmidt, P., \& Heyder, A. (2003).Authoritarianism and ethnocentrism in east and West Germany: Does the system matter?

[11] Uganda Communication Commission Report (2013) Mobile network operator market share.

[12] Uganda Government (2010). A report on the mobile network operators who have partnered with social networking sites to provide mobile internet access and the arrival of cheaper bandwidth via undersea cables

[13] Uganda Telecom (2010) A report on the members of mobile network operators in Uganda and details when Uganda telecom launched its M-Sente services in Uganda

[14] Fredrick F.Reichheld(2003). The one Number you Need to Grow. Harvard Business Review 